\title{
Cost comparison of second-line treatment options for late stage non-small-cell lung cancer: cost analysis for Italy
}

This article was published in the following Dove Press journal:

ClinicoEconomics and Outcomes Research

3 September 2012

Number of times this article has been viewed

\author{
Bjoern Schwander' \\ Simona Ravera ${ }^{2}$ \\ Giovanni Giuliani² \\ Mark Nuijten ${ }^{3}$ \\ Stefan Walzer'
}

'Assessment-in-Medicine (AiM)

$\mathrm{GmbH}$, Loerrach, Germany; ${ }^{2}$ Roche SpA, Monza, Italy; ${ }^{3}$ Ars Accessus

Medica, Amsterdam (Jisp), Netherlands

Correspondence: Bjoern Schwander

Assessment-in-Medicine (AiM)

$\mathrm{GmbH}$, Marie-Curie-Strasse 8,

79539 Loerrach, Germany

$\mathrm{Tel}+497621705105 \quad 12$

Fax +49762170510530

Email info@assessment-in-medicine.de
Background: Lung cancer is the leading cause of cancer deaths worldwide (1.38 million cancer deaths, $18.2 \%$ of the total) and of cancer morbidity (1.61 million new cases, $12.7 \%$ of all new cancers). Currently only three second-line non-small-cell lung cancer (NSCLC) pharmacotherapies are licensed in the European Union: the chemotherapies pemetrexed and docetaxel and the epidermal growth factor receptor tyrosine kinase inhibitor erlotinib. These therapy alternatives have shown a comparable efficacy (survival benefit). In the past, cost comparisons showed that erlotinib was less costly compared to docetaxel, which in turn is cheaper than pemetrexed. Nowadays erlotinib (and docetaxel) are still less expensive than pemetrexed; but docetaxel lost patent protection (basic compound patent) at the end of 2010, so docetaxel drug costs have decreased rapidly and the question remains whether erlotinib is still the least costly therapy alternative in second-line NSCLC.

Material and methods: Italy was selected for base case analysis to compare the total therapy costs, estimated by combining country-specific drug costs, administration costs, and adverse event costs of erlotinib and generic docetaxel in second-line NSCLC therapy. Sensitivity analyses on central input parameters have been performed.

Results: The total costs of treating one patient with erlotinib therapy of $€ 5121$ are lower than the docetaxel costs of $€ 6699$ for the Italian health care setting. Although the drug costs of erlotinib are higher than generic docetaxel (incremental $€ 3770$ ): the costs of intravenous chemotherapy administration (incremental $-€ 4510$ ), and the costs of adverse event therapy (incremental $-€ 837$ ) lead to higher total therapy costs for docetaxel compared to the epidermal growth factor receptor tyrosine kinase inhibitor therapy erlotinib.

Conclusion: The cost comparison findings for Italy show that erlotinib is still the less costly therapy alternative in second-line NSCLC. These results were robust to changes of central input parameters and robust to further potential price decreases for docetaxel.

Keywords: erlotinib, docetaxel, non-small-cell lung cancer, pharmacotherapy, cost analysis, Italy

\section{Background}

Lung cancer is the leading cause of cancer deaths worldwide (1.38 million cancer deaths, $18.2 \%$ of the total) and also of cancer morbidity ( 1.61 million new cases, $12.7 \%$ of all new cancers). ${ }^{1}$

Approximately $80 \%-85 \%$ of lung cancer patients have non-small-cell lung cancer (NSCLC), which is categorized in three major histological subtypes: squamous cell carcinoma, adenocarcinoma, and large-cell carcinoma. ${ }^{2}$ Around $70 \%$ of NSCLC patients present with advanced or metastatic disease (tumor node metastasis [TNM] stages IIIB/IV) at the time of initial diagnosis..$^{3-5}$ These patients with late stage NSCLC 
have a very poor prognosis with just about $7 \%$ of patients with stage IIIB and about $2 \%$ of those with stage IV surviving beyond 5 years. ${ }^{6}$

Once first-line therapy or first-line maintenance therapy have failed, NSCLC patients are often treated with secondline agents, as recommended by major practice guidelines, ${ }^{2,7,8}$ aiming at a palliation of symptoms, a benefit in quality of life, and a prolongation of survival. ${ }^{9}$

In Europe, there are currently only three licensed secondline pharmacotherapy options available in nonsquamous NSCLC: the oral epidermal growth factor receptor (EGFR) tyrosine kinase inhibitor (TKI) erlotinib, and the intravenous chemotherapies docetaxel and pemetrexed. In patients with squamous cell histology, only erlotinib and docetaxel are available. $^{10-12}$

Hence, the second-line NSCLC therapy options for physicians and patients are considerably limited. ${ }^{9,13}$

All these therapy alternatives have shown a comparable survival benefit. In the past this finding of "comparable efficacy" was supported by indirect treatment comparisons ${ }^{14}$ of the pivotal trial data; ${ }^{15-18}$ head-to-head evidence ${ }^{19,20}$ confirms these indirect estimates (Table 1).

Although efficacy is comparable, erlotinib is the only second-line therapy that has shown a statistically significant improvement of patients' quality of life and of lung cancer symptoms, ${ }^{21}$ whereas docetaxel $\left(75 \mathrm{mg} / \mathrm{m}^{2}\right)^{22,23}$ and pemetrexed ${ }^{18}$ have failed to demonstrate comparable benefits. These findings might be due to the nonchemotherapeutic nature of erlotinib, which shows comparable efficacy to chemotherapeutics coupled with a more favorable tolerability profile (see also Table 2).

As the three second-line therapies show similar survival (efficacy) outcomes a cost minimization approach is the health economic standard analysis of choice for comparing these alternatives. ${ }^{24,25}$ Previous cost comparisons (including a review) published prior to loss of patent for docetaxel, showed that erlotinib was less costly than docetaxel, which in turn was less costly than pemetrexed, across different health care settings and different years of publication. ${ }^{26-32}$

Nowadays erlotinib and docetaxel are still less expensive than pemetrexed; but docetaxel lost patent protection (basic compound patent) in most European countries at the end of 2010 , since then the docetaxel drug costs have decreased.

As erlotinib is now facing a generic competitor, the question arises as to whether erlotinib is still the least costly therapeutic alternative in second-line NSCLC therapy.

\section{Material and methods}

In order to answer the research question the Italian health care system has been selected for base case analysis to compare the total therapy costs of erlotinib and generic docetaxel in second-line NSCLC therapy from a health care payer perspective. Total therapy costs have been calculated by summing the country-specific drug costs, administration costs and adverse event costs for erlotinib and docetaxel. The Italian cost data applied are shown in Table 3.

The drug costs have been assessed on the basis of Italian ex-factory prices using the recommended dosing schemes

Table I Survival outcomes of pivotal trials and head-to-head trials of erlotinib, docetaxel and pemetrexed in 2L NSCLC therapy

\begin{tabular}{|c|c|c|c|c|c|c|}
\hline Trial name & Study arms & $\mathbf{N}$ & $\begin{array}{l}\text { Median PFS } \\
\text { in months }\end{array}$ & $\begin{array}{l}\text { Median OS } \\
\text { in months }\end{array}$ & $\begin{array}{l}\text { Survival HR } \\
(95 \% \mathrm{CI})\end{array}$ & $P$-value \\
\hline \multirow[t]{2}{*}{ BR.2 $21^{15}$} & Erlotinib & 488 & 2.2 & 6.7 & $0.70(0.58-0.85)$ & $P<0.001$ \\
\hline & BSC & 243 & 1.8 & 4.7 & & \\
\hline \multirow[t]{2}{*}{$\operatorname{TAX} 317^{16}$} & Docetaxel & 55 & $2.5^{\mathrm{a}, \mathrm{c}}$ & 7.5 & $0.56(0.35-0.88)$ & $P<0.010$ \\
\hline & BSC & 100 & $1.5^{\mathrm{a}, \mathrm{c}}$ & 4.6 & & \\
\hline \multirow[t]{2}{*}{$\operatorname{TAX} 320^{17}$} & Docetaxel & 125 & $2.0^{a, c}$ & 5.7 & NA & NS \\
\hline & $\mathrm{V} / \mathrm{I}$ & 123 & $1.8^{\mathrm{a}, \mathrm{c}}$ & 5.6 & & \\
\hline \multirow[t]{2}{*}{ JMEI ${ }^{18}$} & Pemetrexed & 283 & 2.9 & 8.3 & $0.99(0.82-1.20)$ & $P=0.226$ \\
\hline & Docetaxel & 288 & 2.9 & 7.9 & & \\
\hline \multirow[t]{2}{*}{ HORG ${ }^{19}$} & Erlotinib & 166 & $3.6^{c}$ & 7.9 & $0.96(0.77-1.21)^{\mathrm{b}}$ & $P=0.916$ \\
\hline & Pemetrexed & 166 & $2.7^{c}$ & 8.9 & & \\
\hline \multirow[t]{2}{*}{ TITAN $^{20}$} & Erlotinib & 203 & $1.5^{\mathrm{a}}$ & 5.3 & $0.96(0.78-1.19)$ & $P=0.730$ \\
\hline & $\begin{array}{l}\text { Docetaxel/ } \\
\text { pemetrexed }\end{array}$ & 221 & $2.0^{\mathrm{a}}$ & 5.5 & & \\
\hline
\end{tabular}

Notes: Dosage of recommended $2 \mathrm{~L}$ therapy options within each study: erlotinib $150 \mathrm{mg} /$ day; docetaxel $75 \mathrm{mg} / \mathrm{m}^{2}$ (day I) each 3 weeks [only the labeled dosage was taken into account, hence $100 \mathrm{mg} / \mathrm{m}^{2}$ results are not presented above]; pemetrexed $500 \mathrm{mg} / \mathrm{m}^{2}$ (day I) every 3 weeks, adata have been transferred from weeks to months (divided by 4.33 ; 52 weeks per year divided by 12 months); ${ }^{b}$ HORG trial hazard ratio has been determined by reading out the published Kaplan-Meier curves (as the HR was not published); 'PFS not available therefore TTP is used as a proxy: note that TTP is typically measured from randomization until objective tumor progression and does not include deaths whereas PFS is measured until objective tumor progression or death. Dosage for V/l: $30 \mathrm{mg} / \mathrm{m}^{2} \mathrm{IV}$ (day I, 8, I5) each 3 weeks or ifosfamide $2 \mathrm{mg} / \mathrm{m}^{2}$ (day I, 2, 3).

Abbreviations: 2L, second-line; NSCLC, non-small-cell lung cancer; PFS, progression-free survival; OS, overall survival; HR, hazard ratio; $95 \%$ Cl, $95 \%$ confidence interval; NA, not available; NS, not significant; BSC, best supportive care; V/I, vinorelbine/ifosfamide; TTP, time to progression. 
(erlotinib $150 \mathrm{mg} /$ day; docetaxel $75 \mathrm{mg} /$ body surface area in $\mathrm{m}^{2}$ once [on day 1] every 3 weeks). The proxy treatment duration of 2.5 months has been used for both drugs, according to the pivotal trials' median progression-free survival outcomes shown in Table 1.

According to the European marketing authorization, the injection of docetaxel requires a health care unit specialized for the injection of cytotoxic chemotherapy and the supervision of an oncologist. ${ }^{11}$ In the analysis this charge is assumed the same whether the oncologist attends throughout the infusion or at the inception only. Hence, administration costs of intravenously injected docetaxel were estimated based on the official Italian diagnosis-related groups cost values for an inpatient (50\%) and a hospital-based outpatient $(50 \%)$ administration of cytotoxic chemotherapeutics. The diagnosis related groups tariffs for inpatient and outpatient administration exclude drug costs in most Italian regions and this assumption is held in the analysis. As erlotinib is an oral medication requiring neither the supervision of an oncologist, nor a specialized oncology unit (in contrast to the chemotherapy docetaxel), no administration costs have been applied for erlotinib.

The incidence of adverse events is based on published evidence shown in Table 2.

The cost per adverse event is based on published Italian cost estimates and have been applied to all relevant erlotinib or docetaxel serious adverse events ( $\geq$ grade 3 ) as per Table 3 . The total adverse event cost has been applied as a one-off as the total of the products of adverse event frequencies and respective costs. In cases where more than one incidence value was published (incidence reported in different clinical trials) a conservative approach was applied by taking into account the highest published value for erlotinib and docetaxel to avoid underestimating costs (this occurred more often for docetaxel).

By summarizing the drug costs, administration costs, and adverse event costs the total costs have been calculated for each therapy approach. These total costs of erlotinib and generic docetaxel have been incrementally compared to determine the actual total cost difference between both second-line NSCLC therapy approaches.

Table 2 Overview of serious adverse events ( $\geq$ grade 3 in \%) observed in the pivotal trials and head-to-head trials of erlotinib, docetaxel and pemetrexed in 2L NSCLC therapy

\begin{tabular}{|c|c|c|c|c|c|c|c|c|c|c|}
\hline \multirow{2}{*}{$\begin{array}{l}\text { Trial name } \\
A E \geq \text { grade } 3 \text { in } \%\end{array}$} & \multicolumn{2}{|c|}{ BR.2 $I^{15}$} & \multicolumn{2}{|c|}{ HORG ${ }^{19}$} & \multicolumn{2}{|c|}{$\operatorname{TAX} 317^{16}$} & \multicolumn{2}{|c|}{ TAX32017 } & \multicolumn{2}{|l|}{ JMEI $^{18}$} \\
\hline & ERL & BSC & ERL & PEM & DOX & BSC & DOX & V/I & DOX & PEM \\
\hline Anemia & NR & NR & 0.6 & 1.2 & 5.5 & NR & 0.0 & 2.0 & 4.3 & 4.2 \\
\hline Anorexia/WL & 9.0 & 5.0 & NR & NR & NR & NR & NR & NR & 0.0 & 0.0 \\
\hline Asthenia & NR & NR & 0.6 & 7.2 & 18.2 & 28.0 & 12.0 & 11.0 & NR & NR \\
\hline Cardiac AE & $N R$ & NR & $N R$ & $N R$ & 1.8 & 1.0 & NR & $N R$ & NR & NR \\
\hline Dehydration & 4.0 & 3.0 & NR & NR & NR & NR & NR & NR & NR & NR \\
\hline Diarrhea & 6.0 & 1.0 & 0.6 & 0.6 & 1.8 & 0.0 & 2.0 & 2.0 & 2.5 & 0.4 \\
\hline Fatigue & 19.0 & 23.0 & $N R$ & $N R$ & NR & NR & NR & $N R$ & 5.4 & 5.3 \\
\hline F. neutropenia & NR & NR & 0.0 & 0.0 & 1.8 & NR & 8.0 & 1.0 & 12.7 & 1.9 \\
\hline Fluid retention & NR & NR & NR & NR & 0.0 & NR & 1.0 & 2.0 & NR & NR \\
\hline Infection & 2.0 & 5.0 & $N R$ & NR & 5.5 & 5.0 & NR & $N R$ & 3.3 & 0.0 \\
\hline Leucopenia & NR & NR & 0.0 & 2.4 & NR & NR & NR & NR & NR & NR \\
\hline Mucositis & NR & NR & 0.6 & 0.0 & NR & NR & NR & NR & NR & NR \\
\hline Nausea & 3.0 & 1.0 & 1.2 & 0.0 & 3.6 & 5.0 & 3.0 & 6.0 & 1.8 & 2.6 \\
\hline Neurotoxicity & NR & NR & 0.6 & 0.0 & 3.6 & 6.0 & NR & NR & I.I & 0.0 \\
\hline Neutropenia & NR & NR & 0.0 & 6.6 & 67.3 & NR & 54.0 & 31.0 & 40.2 & 5.3 \\
\hline Ocular toxicity & 1.0 & 1.0 & NR & NR & NR & NR & 1.0 & 3.0 & NR & NR \\
\hline Pulmonary $\mathrm{AE}$ & 1.0 & 1.0 & NR & NR & 20.0 & 30.0 & NR & NR & 1.4 & 0.0 \\
\hline Rash & 9.0 & 0.0 & 5.4 & 0.0 & NR & NR & NR & NR & 0.7 & 0.8 \\
\hline Stomatitis & 1.0 & 0.0 & NR & NR & 1.8 & 0.0 & NR & $N R$ & I.I & I.I \\
\hline Thrombocytopenia & NR & NR & 0.0 & 3.6 & 0.0 & NR & 2.0 & 0.0 & 0.4 & 1.9 \\
\hline Vomiting & 3.0 & 2.0 & 0.6 & 0.0 & 3.6 & 1.0 & 1.0 & 4.0 & I.I & 1.5 \\
\hline
\end{tabular}

Notes: Only grade $\geq 3 \mathrm{AE}$ with an incidence $\geq 1 \%$ were included in the cost assessment; ${ }^{15} \mathrm{Grade} 3-5 \mathrm{AE}$ reported according to Common Toxicity Criteria of the National Cancer Institute (version 2.0); ${ }^{16}$ grade 3-4 AE reported, criteria not specified; ${ }^{17}$ grade 3-4 or severe non-hematologic reported based on Common Toxicity Criteria of the National Cancer Institute, AE not included in that toxicity scale (eg, fluid retention, hypersensitivity reaction, onychodystrophy, and asthenia) were graded as mild (grade I), moderate (grade 2), severe (grade 3), or life-threatening (grade 4); ${ }^{18}$ grade 3-4 hematologic toxicities reported according to Common Toxicity Criteria of the National Cancer Institute (version 2.0); ${ }^{19}$ grade 3-4 AE for hematological and grade 3-5 AE reported for non-hematologic AE reported, grading criteria not specified.

Abbreviations: 2L, second-line; NSCLC, non-small-cell lung cancer; AE, adverse events; ERL, erlotinib; BSC, best supportive care; PEM, pemetrexed; DOX, docetaxel; V/I, vinorelbine/ifosfamide; WL, weight loss; F. neutropenia, Febrile neutropenia; NR, not reported. 
Table 3 Italian cost data applied in the cost comparison of erlotinib and docetaxel in 2L NSCLC therapy

\begin{tabular}{|c|c|c|}
\hline \multirow{2}{*}{$\begin{array}{l}\text { Country } \\
\text { Cost item }\end{array}$} & \multicolumn{2}{|l|}{ Italy } \\
\hline & Costs/€ & Ref \\
\hline $\begin{array}{l}\text { Erlotinib (I mg) } \\
\end{array}$ & 0.44 & 33 \\
\hline Docetaxel (I mg $)^{\mathrm{a}, \mathrm{e}}$ & 2.39 & 33 \\
\hline Inpatient administration ${ }^{d}$ & 1,899 & 34 \\
\hline Daycare administration ${ }^{d}$ & 356 & 34 \\
\hline Anemia & 3,677 & 35 \\
\hline Anorexia/weight loss & 61 & 35 \\
\hline Asthenia/fatigue & 0 & 35 \\
\hline Cardiac AE & $\mathrm{I}, 773^{\mathrm{b}}$ & 36 \\
\hline Dehydration & $2,58 I^{b}$ & 37 \\
\hline Diarrhea & 394 & 35 \\
\hline F. neutropenia & $4,824^{b}$ & 37 \\
\hline Infection & 43 & 35 \\
\hline Nausea & 95 & 35 \\
\hline Neurotoxicity & $0^{c}$ & NA \\
\hline Neutropenia & 154 & 35 \\
\hline Pulmonary AE & $0^{c}$ & NA \\
\hline Rash & 6 & 35 \\
\hline Stomatitis & 45 & 35 \\
\hline Thrombocytopenia & $\mathrm{I}, 323^{\mathrm{b}}$ & 36 \\
\hline Vomiting & 411 & 35 \\
\hline
\end{tabular}

Notes: ${ }^{2}$ The price reflects the lowest available generic price (August 201 I prices), for the calculation of the docetaxel dosage; the Mostellar formula was applied using EU average data on weight and height $\left(72 \mathrm{~kg} ; 170 \mathrm{~cm} ; \mathrm{BSA}=1.84 \mathrm{~m}^{2}\right)$; ${ }^{\text {b }}$ where no lung-cancer specific costs were published $\mathrm{AE}$ estimates referring to other cancer types were applied; 'in some cases where no published data were available estimates given in physician interviews were used; dDRG tariffs for inpatient and outpatient administration exclude drug costs; 'drug costs may be subject to further discounts at hospital (provider) level.

Abbreviations: $2 \mathrm{~L}$, second-line; NSCLC, non-small-cell lung cancer; $\mathrm{AE}$, adverse events; NA, not available; EU, European Union; BSA, body surface area; DRG, diagnosis related groups.

In order to investigate the robustness of results the underlying key input data have been changed in one-way deterministic sensitivity analyses. Additional analyses have been performed using a longer (3.0 months; five docetaxel injections) and a shorter (2.0 months; three docetaxel administrations) therapy time horizon, using varying estimates for the proportion of inpatient administration (high $75 \%$; low $25 \%)$ and higher $(+25 \%)$ and lower $(-25 \%)$ cost estimates for each adverse event. In order to take into account potential further price decreases of generic docetaxel in the future, simulations have been performed applying a further $25 \%$ and a further $50 \%$ price reduction of generic docetaxel.

\section{Results}

As shown in Figure 1, the average total costs of erlotinib therapy of $€ 5121$ are lower than the docetaxel costs of $€ 6699$, in the Italian health care setting under the central assumptions of the analysis.

The erlotinib drug costs of $€ 4950$ are higher than the docetaxel drug costs of $€ 1180$. However, the erlotinib adverse event costs of $€ 171$ are lower than the docetaxel adverse event costs of $€ 1008$. Furthermore, the hospital-based intravenous docetaxel injection costs of $€ 4510$ compare unfavorably to oral erlotinib that requires no administration effort.

According to these base case analyses, the incremental total cost difference of erlotinib vs docetaxel amounts to $-€ 1577$. The robustness of the results has been investigated with sensitivity analyses.

As shown in Figure 2, the sensitivity analysis results confirm the robustness of the "base case" analyses results. Erlotinib was less costly than generic docetaxel, which is shown in the negative incremental total costs for the range of sensitivity analyses undertaken.

The incremental total costs were most sensitive to changes in the distribution of inpatient administrations followed by changes in the therapy duration. The changes in

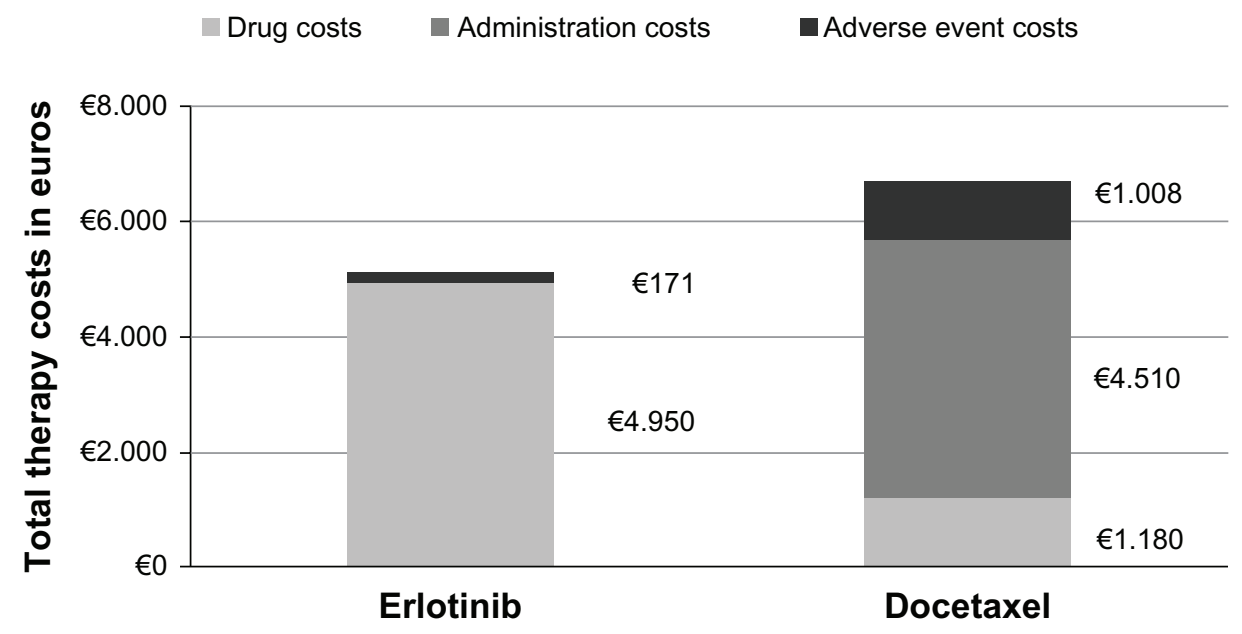

Figure I Cost comparison results of erlotinib vs generic docetaxel as second-line NSCLC therapy in Italy. Abbreviation: NSCLC, non-small-cell lung cancer. 


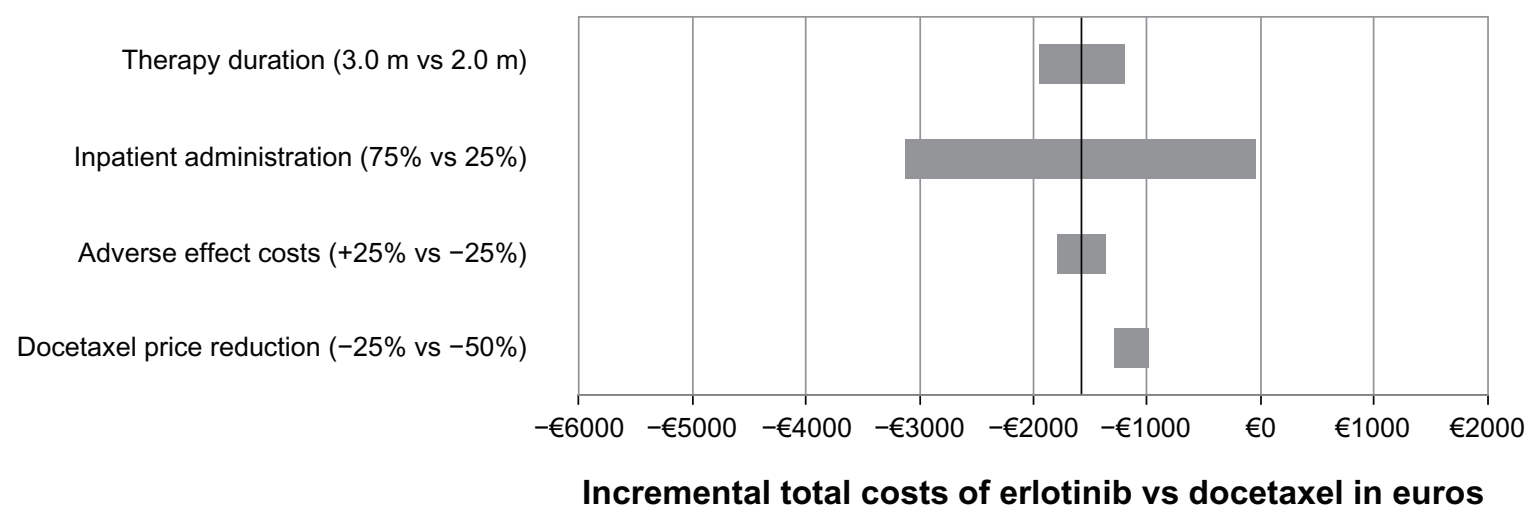

Figure 2 Sensitivity analyses on the incremental total costs of erlotinib vs generic docetaxel as second-line NSCLC (non-small-cell lung cancer) therapy in Italy.

adverse event costs and the simulated further reduction of docetaxel costs of up to $50 \%$ had a limited impact on the incremental total cost results.

\section{Discussion}

The presented health economic analysis investigates the cost impact of the patent protection loss of docetaxel, which has led to a rapid drug cost decrease, in comparison to the patent protected EGFR TKI erlotinib. In the past there was consensus that erlotinib was the least costly pharmacotherapy in second-line NSCLC but the consequences of the price decrease of docetaxel generics has raised doubts as to whether this point of view is still valid and is the rationale for performing this assessment.

The Italian health care system has been used for the base case analysis based on the availability of data. One key limitation is that the cost analysis results presented in this paper are highly dependent on the drug prices, the costs of treating specific adverse events, and especially on the reimbursement rates for the intravenous administration of chemotherapy that may vary from country to country. Hence, the results presented have to be regarded as specific to the Italian health care setting and potential similar findings in other countries and health care settings would need to be confirmed in separate analyses. The reader is cautioned not to apply these results to other health care settings. It is also noted that there is variation of these costs across different regions in Italy.

The research findings for the Italian health care setting show that erlotinib still is the least costly therapy alternative in second-line NSCLC. Although the drug costs of generic docetaxel are lower than the drug costs of erlotinib there are other therapy-related costs that counteract this advantage.

The costs for the intravenous chemotherapy administration have been identified as the key docetaxel cost driver.
The docetaxel label indicates that injection of the drug requires a unit specialized for the injection of cytotoxic chemotherapy and the supervision of an oncologist, which results in high additional efforts for the health care payers. In contrast, such administration costs are not required for the oral EGFR TKI erlotinib. One limitation related to the simulation of the administration costs is the lack of information related to the proportion of inpatient administrations performed for docetaxel. The inpatient administrations are more costly than the outpatient administrations (Table 3) which may have an impact on the cost comparison results. Hence sensitivity analyses were performed investigating a range from $25 \%$ up to $75 \%$ of inpatient administrations, without having a major impact on the cost comparison results (in each scenario erlotinib was less costly compared to docetaxel).

Median progression free survival has been used as a proxy for treatment duration due to the availability of data. As shown in Table 1, progression-free survival/time to progression varies for docetaxel from 2.0 to 2.5 months and for erlotinib from 1.5 to 3.6 months. Mean progression-free times have not been used as they require further survival analysis.

Furthermore, as erlotinib shows a more favorable tolerability profile the costs of treating adverse events are lower for erlotinib than for the cytotoxic chemotherapy, which again results in additional effort for health care payers due to docetaxel. In addition, the influence of this cost driver has been investigated in sensitivity analyses, by varying the underlying costs of single adverse events $( \pm 25 \%)$, without having a major impact on the cost comparison results.

In specific sensitivity analyses, it was assumed that docetaxel costs might decrease further in the future. Hence an additional $25 \%$ and a $50 \%$ drug cost reduction was simulated for generic docetaxel, in order to test whether the research findings are robust to such possible changes in the future, 
without having a major impact on the cost comparison results.

\section{Conclusion}

In summary, the presented assessment focusing on the Italian health care system has found that docetaxel therapy costs, apart from drug costs, consist of two additional major cost components: namely the intravenous chemotherapy administration costs and the adverse event therapy costs. These "hidden costs" lead to higher total therapy costs of (generic) docetaxel compared to the EGFR TKI therapy erlotinib, that largely consist of drug costs which are transparent and easier to predict for the health care payers.

The findings for Italy show that under the central assumptions of the analysis, erlotinib is the least costly therapy alternative in second-line NSCLC, considering generization of docetaxel. These results were robust to changes of central input parameters and robust to potential further price decreases of docetaxel.

\section{Acknowledgments}

This work was funded by Roche SpA, Italy. Roche was involved in gathering the country-specific input data, in reviewing the analysis results and in reviewing the manuscript.

\section{Disclosure}

The authors report no conflicts of interest in this work.

\section{References}

1. Ferlay J, Shin HR, Bray F, Forman D, Mathers C, Parkin DM. Estimates of worldwide burden of cancer in 2008: GLOBOCAN 2008. Int J Cancer. 2010;127(12):2893-2917.

2. D’Addario G, Früh M, Reck M, Baumann P, Klepetko W, Felip E; for ESMO Guidelines Working Group. Metastatic non-small-cell lung cancer: ESMO Clinical Practice Guidelines for diagnosis, treatment and follow-up. Ann Oncol. 2010;21 Suppl 5:116-119.

3. Blanchon F, Grivaux M, Collon T, et al. Epidémiologie du cancer bronchique primitif pris en charge dans les centres hospitaliers généraux français. Rev Mal Respir. 2002;19(6):727-734.

4. Yang P, Allen MS, Aubry MC, et al. Clinical features of 5,628 primary lung cancer patients: experience at Mayo Clinic from 1997 to 2003. Chest. 2005;128(1):452-462.

5. Howlander N, Noone A, Krapcho M, et al. SEER Cancer Statistics Review, 1975-2008 [updated 2011]. Available from: http://seer.cancer. gov/csr/1975_2008/. Accessed September 15, 2011.

6. Goldstraw P, Crowley J, Chansky K, et al. The IASLC Lung Cancer Staging Project: proposals for the revision of the TNM stage groupings in the forthcoming (seventh) edition of the TNM Classification of malignant tumours. J Thorac Oncol. 2007;2(8):706-714.

7. Azzoli CG, Baker S Jr, Temin S, et al. American Society of Clinical Oncology Clinical Practice Guideline update on chemotherapy for stage IV non-small-cell lung cancer. J Clin Oncol. 2009;27(36):6251-6266.

8. NCCN Practice Guidelines in Oncology - Non-Small Cell Lung Cancer [updated 2011]. Available from: http://www.nccn.org/professionals/ physician_gls/f_guidelines.asp. Accessed September 15, 2011.
9. Maione P, Rossi A, Bareschino MA, et al. Factors driving the choice of the best second-line treatment of advanced NSCLC. Rev Recent Clin Trials. 2011;6(1):44-51.

10. Erlotinib - Summary of Product Characteristics [updated June 7, 2011]. Available from: http://www.ema.europa.eu/docs/en_GB/ document_library/EPAR_-_Product_Information/human/000618/ WC500033994.pdf. Accessed September 15, 2011.

11. Docetaxel - Summary of Product Characteristics [updated February 3, 2011]. Available from: http://www.ema.europa. eu/docs/en_GB/document_library/EPAR_-_Product_Information/ human/002032/WC500101758.pdf. Accessed September 15, 2011.

12. Pemetrexed - Summary of Product Characteristics [updated February 23, 2011]. Available from: http://www.ema.europa.eu/docs/en GB/document_library/EPAR_-_Product_Information/human/000564/ WC500025611.pdf. Accessed September 15, 2011.

13. Scagliotti GV. Beyond first-line treatment: expanding the options. Proceedings of the 2nd International Thoracic Oncology Congress Dresden (ITOCD), published in Session: Treatment strategies to extend survival in advanced NSCLC; 2010 Sep 16- 18; Dresden, Germany. ITOCD 2010. http://www.itocd.com/.

14. Hawkins N, Scott DA, Woods BS, Thatcher N. No study left behind: a network meta-analysis in non-small-cell lung cancer demonstrating the importance of considering all relevant data. Value Health. 2009;12(6):996-1003.

15. Shepherd FA, Rodrigues PJ, Ciuleanu T, et al. Erlotinib in previously treated non-small-cell lung cancer. $N$ Engl J Med. 2005;353(2):123-132.

16. Shepherd FA, Dancey J, Ramlau R, et al. Prospective randomized trial of docetaxel versus best supportive care in patients with non-small-cell lung cancer previously treated with platinum-based chemotherapy. J Clin Oncol. 2000;18(10):2095-2103.

17. Fossella FV, DeVore R, Kerr RN, et al. Randomized phase III trial of docetaxel versus vinorelbine or ifosfamide in patients with advanced non-small-cell lung cancer previously treated with platinum-containing chemotherapy regimens. The TAX 320 Non-Small Cell Lung Cancer Study Group. J Clin Oncol. 2000;18(12):2354-2362.

18. Hanna N, Shepherd FA, Fossella FV, et al. Randomized phase III trial of pemetrexed versus docetaxel in patients with non-small-cell lung cancer previously treated with chemotherapy. J Clin Oncol. 2004;22(9):1589-1597.

19. Vamvakas L,Agelaki S, Kentepozidis NK, et al. Pemetrexed(MTA) compared with erlotinib (ERL) in pretreated patients with advanced non-small-cell lung cancer (NSCLC): Results of a randomized phase III Hellenic Oncology Research Group trial. Proceedings of the American Society of Clinical Oncology (ASCO) Annual Meeting; 2010 June 4-8; Chicago, IL, USA. American Society of Clinical Oncology; J Clin Oncol. 2010;28(15S):7519.

20. Ciuleanu T, Stelmakh L, Cicenas S, Esteban E. Erlotinib versus docetaxel or pemetrexed as second-line therapy in patients with advanced non-small-cell lung cancer (NSCLC) and poor prognosis: efficacy and safety results from the phase III TITAN study: Proceedings of the Chicago Multidisciplinary Symposium in Thoracic Oncology; 2010 Dec 9-11; Chicago, IL, USA; American Society for Radiation Oncology; J Thorac Oncol. 2010;5(12):LBOA5.

21. Bezjak A, Tu D, Seymour L, et al. Symptom improvement in lung cancer patients treated with erlotinib: quality of life analysis of the National Cancer Institute of Canada Clinical Trials Group Study BR.21. J Clin Oncol. 2006;24(24):3831-3837.

22. Dancey J, Shepherd FA, Gralla RJ, Kim YS. Quality of life assessment of second-line docetaxel versus best supportive care in patients with non-small-cell lung cancer previously treated with platinum-based chemotherapy: results of a prospective, randomized phase III trial. Lung Cancer. 2004;43(2):183-194.

23. Miller V, Fossella FV, De Vore R, et al. Docetaxel Benefits Lung Cancer Symptoms and Quality of Life in a Randomized Phase III Study of Non-Small Cell Lung Cancer Patients Previously Treated with Platinum-Based Therapy: Proceedings of the American Society of Clinical Oncology (ASCO) Annual Meeting; 1999 May 15-19, 1999; Atlanta, GA, USA. American Society of Clinical Oncology, 1999. 
24. Newby D, Hill S. Use of pharmacoeconomics in prescribing research. Part 2: cost-minimization analysis - when are two therapies equal? J Clin Pharm Ther. 2003;28(2):145-150.

25. Briggs AH, O'Brien BJ. The death of cost-minimization analysis? Health Econ. 2001;10(2):179-184.

26. Lyseng-Williamson KA. Erlotinib: a pharmacoeconomic review of its use in advanced non-small cell lung cancer. Pharmacoeconomics. 2010;28(1):75-92.

27. Araújo A, Parente B, Sotto-Mayor R, et al. An economic analysis of erlotinib, docetaxel, pemetrexed and best supportive care as second or third line treatment of non-small cell lung cancer. Rev Port Pneumol. 2008;14(6):803-827.

28. Capri S, Orabito A, Rillio G. Economic evaluation of erlotinib, docetaxel and pemetrexed as second line therapy in non-small cell lung cancer [in Italian]. Pharmacoeconomics Ital Res Articles. 2010;9(2):113-124.

29. Carlson JJ, Reyes C, Oestreicher N, Lubeck D, Ramsey SD, Veenstra DL. Comparative clinical and economic outcomes of treatments for refractory non-small cell lung cancer (NSCLC). Lung Cancer. 2008;61(3):405-415.

30. Doral Stefani S, Giorgio Saggia M, Vicino dos Santos EA. Costminimisation analysis of erlotinib in the second-line treatment of non-small-cell lung cancer: a Brazilian perspective. J Med Econ. 2008;11(3):383-396.

31. Gatzemeier U, Pirk O, Gabriel A, Kotowa W. Second-Line-Therapy for Non-Small Cell Lung Cancer (NSCLC) - a Retrospective Cost Analysis. Tumor Diagnostik und Therapie. 2008;29(4):211-217.
32. Kotowa W, Gatzemeier U, Pirk O, Gabriel A, Heigener D. A comparison of the estimated costs of erlotinib, docetaxel and pemetrexed for the second-line treatment of non-small cell lung cancer from the German health care perspective. J Med Econ. 2007;10(3):255-271.

33. Italian ex-factory costs of erlotinib and docetaxel [updated 2011]. Available from: http://www.informatorefarmaceutico.it/. Accessed August 6, 2011.

34. Chemotherapy administration costs in Italy (Tariffa unica convenzionale per le prestazioni di assistenza ospedaliera regole e tarife valide per l'anno 2009; Inpatient DRG 17 M 410; Daycare DRG 17 M 410) [updated 2010]. Available from: http://www.regioni.it/mhonarc/ details_confpres.aspx?id=172630. Accessed August 18, 2011.

35. Banz K, Bischoff H, Brunner M, et al. Comparison of treatment costs of grade $3 / 4$ adverse events associated with erlotinib or pemetrexed maintenance therapy for patients with advanced non-small-cell lung cancer (NSCLC) in Germany, France, Italy, and Spain. Lung Cancer. 2011;74(3):529-534.

36. Mickisch G, Gore M, Escudier B, Procopio G, Walzer S, Nuijten M. Costs of managing adverse events in the treatment of first-line metastatic renal cell carcinoma: bevacizumab in combination with interferonalpha2a compared with sunitinib. Br J Cancer. 2010;102(1):80-86.

37. Brown B, Diamantopoulos A, Bernier J, et al. An economic evaluation of cetuximab combined with radiotherapy for patients with locally advanced head and neck cancer in Belgium, France, Italy, Switzerland, and the United Kingdom. Value Health. 2008;11(5):791-799.
ClinicoEconomics and Outcomes Research

\section{Publish your work in this journal}

ClinicoEconomics \& Outcomes Research is an international, peerreviewed open-access journal focusing on Health Technology Assessment, Pharmacoeconomics and Outcomes Research in the areas of diagnosis, medical devices, and clinical, surgical and pharmacological intervention. The economic impact of health policy and health systems

\section{Dovepress}

organization also constitute important areas of coverage. The manuscript management system is completely online and includes a very quick and fair peer-review system, which is all easy to use. Visit http://www.dovepress.com/testimonials.php to read real quotes from published authors. 